\title{
When is enough enough? Accurate measurement and the integrity of scientific research
}

\section{H. Otto Sibum}

Avdelningen för vetenskapshistoria, Uppsala University, Sweden

\begin{abstract}
At a meeting of the Physical Society of London in 1925 participants expressed their concerns regarding a recent suggestion by the Australian physicist T. H. Laby for replicating the established value of the mechanical equivalent of heat. This rather controversial discussion about the value of redetermining this numerical fact brings to light different understandings of the moral economy of accuracy in scientific work; it signals a distinctive new stage in the historical understanding of accuracy and precision and the moral integrity in conducting research.
\end{abstract}

\section{Keywords}

Replication, research integrity, precision, accuracy, mechanical equivalent of heat

In December 1925 the London Physical Society received a critical examination of experimental determinations of a physical constant, the mechanical equivalent of heat, submitted by the Australian physicist T. H. Laby. Already in the 1840s the Manchester brewer James Prescott Joule had established this ratio of the mechanical work employed in producing a certain amount of heat through the mechanical friction of water. Since then, many nineteenth-century physical scientists had taken up the task to redetermine its value because they shared the insight of the German physiologist Ernst Wilhelm Brücke that

amongst all numbers which have been and will be next examined, the numerical value to be investigated is of such high importance that no other can compete with it. In the future there will be no part of the physical sciences in which this number does not play an essential role. No less important is its meaning for practical applications by preparing the basis for the estimate of

\section{Corresponding author:}

H. Otto Sibum, Avdelningen för vetenskapshistoria, Uppsala University, Box 629, 75I 26 Uppsala, Sweden.

Email: otto.sibum@idehist.uu.se 


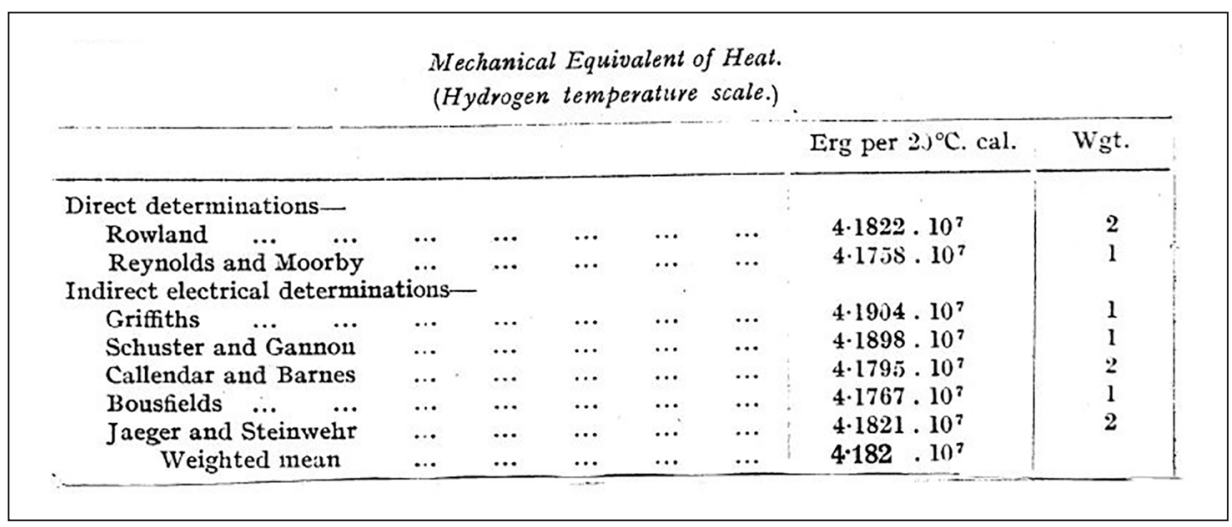

Figure I. Table of determinations of the mechanical equivalent of heat.

Source: T. H. Laby, "Critical Discussion of the Determinations of the Mechanical Equivalent of Heat," Proceedings of the Royal Society of London 38 (1926): 169-75, 172.

any work producing system. Simultaneously, it will show us the limit above which we should not hold out any hopes of gaining more work. ${ }^{1}$

In fact in the course of the century this physical constant had become the building block of modern physics. Laby's critical examination presented at the 1925 meeting was an attempt to correct previous determinations of the value of the mechanical equivalent of heat for errors not fully taken into account at the time when they were made. Laby weighted the results according to the relative importance he attached to them and he proposed a final mean value (Fig. 1). At the meeting these efforts were controversially discussed. This paper is devoted to this controversy and the immense labor that went into the collective establishment of this physical constant. The suggested focus on the changing practices of improving the accuracy of these numerical measurements reveals the hidden sociocultural dimensions of conducting research in this branch of the physical sciences. Establishing trust in the methods used and the findings that result from them are key elements of a practiced research integrity. An extended treatment of the earlier history of the determination of this physical constant will elucidate the historical dimensions of the discussion at the London Physical Society about the value of redetermining this numerical fact and their member's implicitly shared assumptions about research integrity. Furthermore, the controversy reveals a distinctive new stage in the historical

1. Ernst Brücke, 1851, in: Die Mechanik der Wärme in Gesammelten Schriften von Robert Mayer. Dritte ergänzte und mit historisch-literarischen Mitteilungen versehene Auflage. Herausgegeben von Jacob J. Weyrauch (Stuttgart, 1893), p.296. On Joule's classical experiment see James Prescott Joule, "On the Mechanical Equivalent of Heat," Philosophical Transactions of the Royal Society of London 140 (1850): 61-82. For an extended discussion of the development of this scientific fact see H. Otto Sibum, "The Number of the Century: A History of a Scientific Fact," in: Praemium Erasmianum Foundation (ed.), Wetenschap en samenleving. Praemium Erasmianum Yearbook 2005 [Science and Society. Praemium Erasmianum jaarboek 2005] (Amsterdam, 2006), pp.61-95. 
understanding of accuracy and precision and the moral integrity in conducting research that finally led the involved actors to agree on the final value of this physical constant.

At the December meeting of the Physical Society of London in 1925 the Cambridgeeducated physicist G. M. Clark expressed his concerns regarding another attempt at replicating the established value: "I doubt whether much is gained by discussing the results of other observers by making known corrections that arise through the light of later knowledge." Griffiths, noted that he viewed "with certain misgivings attempts to correct old work unless made by the investigators themselves, as they alone are acquainted with all the facts concerning the apparatus." 3 Hence when the Australian physicist T. H. Laby proposed his critical examination it seemed that most of the leading scientists present at the physicists' gathering in London "had little faith in the values of physical constants obtained by applying corrections long after the date of the observations." 4

It was not at all unusual to draw attention to slight discrepancies between experimenters' results. Within the scientific community it was even the daily experience of experimentalists to expect errors to arise. But it was commonly understood that they had to be within the limits of reasonable agreement. Hence one would have expected that Laby's presentation of a table of deviating experimental results would be a most welcome endeavor. In fact a public discussion of diverging values might even elicit greater communal trust than claims of a perfect match of previously measured values. Why then were these critical and even defensive statements about Laby's replication of this experiment enunciated? It seems Laby's attempt to weigh the experimental results according to their level of accuracy in performance challenged the collectively shared understanding of reasonable agreement. Moreover, Laby's proposal could be taken as questioning the research integrity of the involved scientists.

Today research integrity is conventionally understood as "conducting research in a way which allows others to have trust and confidence in the methods used and the findings that result from this." Conducting research with integrity implies that researchers demonstrate sufficient accuracy in performance that meets professional standards. Accuracy has become the scientific community's moral backbone and the reproducibility of experiments, which hinges on accurate performance (of measurements), has become one of the key methodological features of research integrity. But as ongoing debates in scientific journals indicate, reproducing experiments remains a vexed matter. Thomas Kuhn pointed to this 'fifth law of thermodynamics', that is, the universally shared experience that "no experiment gives quite the expected numerical results." $\mathrm{He}$ even reminded us that

2. G. M. Clark in T. H. Laby, "Critical Discussion of the Determinations of the Mechanical Equivalent of Heat," Proceedings of the Physical Society of London 38 (1926): 169-75, 173.

3. Ezer Griffiths in ibid., p.173.

4. F. E. Smith in ibid.

5. University of Bath, "Definition of Research Integrity: What Research Integrity Means to Us and How we Make Sure Our Research Continues to Meet the Highest Standards," < https:// www.bath.ac.uk/corporate-information/definition-of-research-integrity/>.

6. As Thomas Kuhn explains, the first three laws of thermodynamics are quite well known; the 'fourth law' states that no piece of experimental apparatus works the first time it is set 
what scientists seek in numerical tables is not usually 'agreement' at all, but what they often call 'reasonable agreement'. Furthermore, if we now ask for a criterion of 'reasonable agreement', we are literally forced to look in the tables themselves. Scientific practice exhibits no consistently applied or consistently applicable external criterion. 'Reasonable agreement' varies from one part of science to another, and within any part of science it varies with time. ${ }^{7}$

The sociologist of science Harry Collins explicated in great detail the troubles with replication of experiments by coining the phrase "experimenter's regress." In a recent interview he summed up that point by stating: "Scientists cannot know if a replication falsifies an experimental finding unless they also know that the work has been done adequately, and since experimental skill is tacit-knowledge-laden, the argument can go on forever. I call this 'the experimenter's regress'."8

Judgments regarding what is considered to be an adequate performance of experimental work (precision measurement) or reasonable agreement always depend on the values and practices shared by a community of physical scientists. Or as Steven Shapin has put it:

in order to say that experimental results 'fit' or 'confirm' a hypothesis, one has to implement some procedure for identifying when fit is good enough. One could, of course, endeavour explicitly to formulate a rule for 'good enough fitting', only to find oneself in need of a further rule to determine how the fitting rule ought to be applied. In practice, . . . adequate fit is characterized through its instantiation by a relevant community of reasonable people. ${ }^{9}$

The critical discussion of the determination of the mechanical equivalent of heat performed at the Physical Society in London provides important insights into what members

up; and the 'fifth law' has been examined quite intensely by, amongst others, H. M. Collins, Changing Order: Replication and Induction in Scientific Practice (London, Beverly Hills, and New Delhi: Sage, 1985); Steven Shapin and Simon Schaffer, Leviathan and the AirPump (Princeton, NJ: Princeton University Press, 1985); H. O. Sibum, "Reworking the Mechanical Value of Heat: Instruments of Precision and Gestures of Accuracy in Early Victorian England," Studies in History and Philosophy of Science Part A 26 (1995): 73-106; and Thomas Kuhn, "The Function of Measurement in Modern Physical Science," in Thomas Kuhn, The Essential Tension: Selected Studies in Scientific Tradition and Change (Chicago and London: University of Chicago Press, 1977), pp.178-224.

7. Kuhn, "The Function of Measurement," pp.184-5 (note 6).

8. H. M. Collins, "Questions and Answers with Harry Collins," in Physics Today, May 13, 2015; on replication and experimenter's regress in particular see H. M. Collins, Changing Order: Replication and Induction in Scientific Practice (London, Beverly Hills, and New Delhi: Sage, 1985); on tacit knowledge see H. M. Collins, Tacit and Explicit Knowledge (Chicago and London: University of Chicago Press, 2010).

9. Steven Shapin, A Social History of Truth, Civility and Science in Seventeenth-Century England (Chicago and London: University of Chicago Press, 1994), p.310; on this see also Kuhn, "The Function of Measurement," pp.178-224 (note 6); on the problem of replication of experiment see, in particular, Collins, Changing Order (note 8) and his recent article "Reproducibility of Experiments: Experimenters' Regress, Statistical Uncertainty Principle, and the Replication Imperative," in Harald Atmansbacher and Sabine Maasen (eds), Reproducibility: Principles, Problems, Practices, and Prospects (Hoboken, NJ: John Wiley \& Sons, 2016), ch.4. 
of this society considered research integrity to entail. These actors' practical decisions about variation in experimental results and standards of precision and accuracy in particular were, in the end, moral judgments that have a social history. Nineteenth-century practitioners of science understood accuracy and precision rather differently than today; for them accuracy meant 'doing with care' (lat. accurare), referring to the quality of their workmanship, whereas precision described the instruments and their quality. Quite often both terms were used synonymously and it was not before the early twentieth century that our modern conceptions were fully established within the scientific community: that is to say 'accuracy' now referring to the closeness of measured values to the actual (true) value and precision indicating the closeness of the measured values to each other. In Laby's time reasonable agreement about the correct value of this numerical scientific fact was achieved only because this international community of scientists successfully communicated about the explicit and implicit assumptions involved in the ideals and practices of precision and accuracy employed in this precision measurement experiment. Only that provided the means to agree on when enough is enough. ${ }^{10}$

\section{Troubles with replication}

The critical discussion having occurred in 1925 at the meeting of the Physical Society of London and been published in 1926 provides a unique opportunity for the historian to reveal the implicitly shared assumptions held in the early twentieth-century scientific community reassuring themselves about whether reasonable agreement about measured values had been achieved and what meaning replication of experiment played in particular. Laby's approach to assessing previous attempts of determining the value of the mechanical equivalent of heat beginning with the direct determinations of $\mathrm{J}$ by Henry $\mathrm{A}$. Rowland from the late 1870 s confronted a few members of the 1925 gathering with a history of science they had actively participated in. But in order to fully grasp the society's self-understanding and implicitly shared assumptions about research integrity we need to go even further back in time and sketch briefly the history of the determination of $\mathrm{J}-$ this "most important constant of nature" as it was labeled in the second half of the nineteenth century and undoubtedly known by T. H. Laby, J. K. Roberts, and E. O. Hercus, as well as the members of the Physical Society of London present at the meeting.

In the 1860 s British physicists who worked on the science of energy regarded the mechanical equivalent of heat as proof of energy conservation and the true numerical representation of nature - it served them as the key element for the envisaged absolute system of units. An exact value of the mechanical equivalent of heat would provide the

10. On the changing meanings of 'accuracy' and 'precision' in the physical sciences see M. Norton Wise (ed.) The Values of Precision (Princeton, NJ: Princeton University Press, 1995), in particular his "Introduction", pp.3-13; Simon Schaffer, "Accurate Measurement is an English Science," pp.135-72 (chapter 6, in Wise, 1995) and Kathryn M. Olesko, "The Meaning of Precision: The Exact Sensibility in Early Nineteenth-Century Germany," pp.103-4 (chapter 5, in Wise, 1995); H. Otto Sibum, "Reworking" (note 6); Graeme J. N. Gooday, The Morals of Measurement: Accuracy, Irony, and Trust in Late Victorian Electrical Practice (Cambridge: Cambridge University Press, 2004), pp.40-81. 
quantitative unifying structure for the many phenomena displaying correlation of forces. Once this fact was established as a true representation of nature, the calibration of all other natural forces, such as electricity, magnetism, and chemical forces, with mechanical work was possible. It seemed that everything was at hand in order to set up this "coherent system," as the British Association for the Advancement of Science (BAAS) had called their measures. ${ }^{11}$ Their standards program was intimately linked with the telegraphy industry of the British Empire and demanded the highest degrees of accuracy and precision. Reports about the work from the 1860 s to 1880 s show clearly the challenge centering on precision measurement that lay in this highly competitive project. ${ }^{12}$ Even for the development of experimental thermodynamics and electrodynamics as an exact science this extreme accuracy of measurement became the obligatory requirement. From 1851, precisely a year after Joule's publication, “On the Mechanical Equivalent of Heat," the Kew Observatory announced that they had taken steps with a view to producing "instruments, under their own superintendence, for distribution to institutions and individuals who might require accurate standards of reference." ${ }^{13}$ Furthermore, laboratories were set up in many universities in order to be able to learn and improve upon the appropriate use of instruments of precision. Not only in Britain but also in the whole of Europe, the culture of precision was reaching its peak. By the 1870 s, in the physical sciences most often 'to know' meant 'to measure'. ${ }^{14}$

Yet, despite their success in promoting the British science of energy, the universal principle of energy conservation was still called into question from several points of view. The Oxford-educated Reverend Highton, for example, described the subject as "of extreme importance both for the interpretation of physical phenomena and for determining what limits are assigned by the stern laws of Nature to the exercises of man's mechanical and scientific skill." 15

Finally Highton claimed that one could state the equivalency of heat and force that Joule had demonstrated in several experiments with certainty. However, he was unwilling

11. "Report of the Committee Appointed by the British Association on Standards of Electrical Resistance," British Association for the Advancement of Science Reports (London, 1864): 111-77.

12. M. Norton Wise and Crosbie Smith, Energy and Empire: A Biographical Study of Lord Kelvin (Cambridge: Cambridge University Press, 1989); Simon Schaffer, “A Manufactory of Ohms: Late Victorian Metrology and Its Instrumentation," in S.E. Cozzens and R. Bud (eds), Invisible Connections (Bellingham: SPIE, 1992), pp.23-56; Schaffer, "Accurate Measurement," (note 10); Bruce J. Hunt, "The Ohm is where the Art is. British Telegraphic Engineers and the Development of Electrical Standards," Osiris 9 (1994): 48-63; Crosbie Smith, The Science of Energy: A Cultural History of Energy Physics in Victorian Britain (London: Athlone Press, 1998).

13. J. Welsh, "On the Graduation of Standard Thermometers at the Kew Observatory," BAAS Report (1853): 34-6. For Joule's main publication see Joule, “On the Mechanical Equivalent of Heat" (note 1).

14. On first practical physics courses see Friedrich Kohlrausch, Leitfaden der praktischen Physik zunächst für das physikalische Praktikum in Göttingen (Leipzig, 1870).

15. H. Highton, "On the Mechanical Equivalent of Heat," Proceedings of Literary and Philosophical Society 10 (1871): 147. 
to accept an absolute limitation to human and nature's productivity. He also suggested that this numerical fact was only valid in mechanics and not in the fields of electricity or magnetism. It would therefore be wrong to deduce a universal principle from this numerical fact. ${ }^{16}$ In 1867 a major controversy even started because Joule himself had replicated his own experiments, through which the constant was first established.$^{17}$ In these new experiments Joule heated water by means of employing a current-carrying copper wire that was put into a fixed amount of water and connected to a battery. In employing this electrical experimental set-up he had to rely on an electrical unit, the ohm, which would allow him to calculate exactly the electrical energy of the current-carrying copper wire required to heat the water. Eventually in his trials he obtained a different value for the equivalent far beyond what was accepted as the limits of reasonable agreement with the known value. On top of that, Joule claimed that he had performed his new experiments "with more accuracy" than his old experiments. This statement threw doubt upon the accuracy of performance of the prestigious research team that had been established by the BAAS to determine the electrical unit, the ohm. ${ }^{18}$ British science of energy was beginning to run into a crisis. Even the first Cambridge Professor of Experimental Physics James Clerk Maxwell involved himself in redetermining the mechanical equivalent of heat with a new direct method designed by him. "I think it a plan free from mechanical difficulties and in a lofty room with plenty of mercury and strong ironwork, and cherub aloft to read the level \& the Thermometer and a monkey to carry up mercury to him (called Quicksilver Jack) the thing might go on for hours." 19

This metaphorical description indicates Maxwell's doubts about the previous experiments: the heat radiation of the experimenter's body disqualified humans doing the experiment such that only a disembodied cherub could be the expert in reading temperatures with accuracy. But the actual underlying concern was the dynamical theory of heat and the experiment's implications about the nature of heat. Joule wrote in 1869 to Thomson: "Our sudden post has frozen up the moral \& intellectual virtue of our philosophers. . . This is the time for new proofs now the hermetical conclave are preparing to put down the dynamical theory as heretical." 20

Meanwhile several strategies were developed to solve these problems in which Maxwell played the part of a mediator between the involved groups. ${ }^{21}$ The American

16. See H. Highton, "On the Relations Between Chemical Change, Heat, and Force - with a Special View to the Economy of Electro-dynamic Engines," The Quarterly Journal of Science and Annals of Mining, Metallurgy, Engineering, Industrial Arts, Manufactures, and Technology 1 (1871): 77-94, 89.

17. J. P. Joule, "Determination of the Dynamical Equivalent of Heat from the Thermal Effects of Electric Currents," BAAS Report (1867): 512-22.

18. W. Thomson, Popular Lectures and Addresses, Vol. 1 (London, 1889), pp.73-136, 133-4. On the committee appointed by the British Association on Standards of Electrical Resistance see Simon Schaffer, "A Manufactory of Ohms: Late Victorian Metrology and Its Instrumentation" (note 12); Schaffer, "Accurate Measurement” (note 10).

19. Maxwell to Tait, December 23, 1867, Cambridge University Library, MSS Add 7655 1b.

20. Joule to Thomson, December 29, 1869, Cambridge University Library MSS Add 7342 J287.

21. For studies of how these issues were resolved see H. Otto Sibum, "An Old Hand in a New System," in Jean-Paul Gaudillière and Ilana Löwy (eds), The Invisible Industrialist: 
engineer and physicist Henry A. Rowland realized during a one-year stay in Europe that the different values experimentalists had obtained in their measurements of fundamental units shook the new energy physics to its fundaments. Rowland regarded a new determination of the mechanical equivalent of heat to be the key investigation necessary in order to establish "one of the most important constants of nature." 22 Only an exact value in absolute measures would qualify as a true representation of nature and therefore provide the required sinew for the rising international community of modern physics. But to achieve this would require changes in practicing science, for example an intensive collaboration between instruments makers, engineers, and laboratory sciences. Therefore, as the founding director of the physics laboratory at Johns Hopkins University, Rowland explained to the board of trustees that in modern times "it is useless to expect anything from extemporized apparatus." 23 Modern physics needed the highest standards from the workshop, its tools and machinery, and in particular excellent craftsmanship from the instrument maker, to provide the researcher with precision instruments of outstanding quality. Furthermore, a course in physics well-balanced between mathematical and experimental methods "will not only meet a long-felt need in this country and hoped that it will attract that class of students who would otherwise go to Germany to pursue their studies" but also train "physicists of precision." Only such a regime would be able to make "the modern order of things" work.

Rowland coined this phrase on the occasion of the opening of the new physics laboratory. According to him the modern order of things began with Galileo, who was the first researcher who trusted his own reasoning only because he had tested his ideas experimentally. ${ }^{24}$ In Rowland's laboratory the new generation of students would have to learn

to test their knowledge constantly and thus see for themselves the sad results of vague speculation; they must learn by direct experiment that there is such a thing in the world as truth and that their own mind is most liable to error. They must try experiment after experiment and

Manufactures and the Production of Scientific Knowledge (Houndsmill: Macmillan, 1998), pp.23-57; H. Otto Sibum "Exploring the Margins of Precision," in Marie-Noelle Bourguet, Christian Licoppe, and H. Otto Sibum (eds), Instruments, Travel and Science: Itineraries of Precision from the Seventeenth to the Twentieth Century (London and New York: Routledge, 2002), pp.216-42; and Crosbie Smith, The Science of Energy (note 12).

22. Henry A. Rowland "On the Mechanical Equivalent of Heat, with Subsidiary Researches on the Variation of the Mercurial from the Air Thermometer, and on the Variation of the Specific Heat of Water," Proceedings of the American Academy of Arts and Sciences (1879-80): 75-200.

23. Henry A. Rowland, Report to the Board of Trustees, undated, Johns Hopkins University, The Milton S. Eisenhower Library, Special Collections (hereafter JHU) Ms 6, pp.17-18. Although he was a great admirer of Faraday and other British scientists, Rowland wanted to make it clear that the "science of the future" had to go beyond those forms of experimental practice, based as that was on improvising performances. Compare H. Otto Sibum "An Old Hand" (note 21).

24. Henry A. Rowland, "Lecture Given at the Opening of the Physics Laboratory," JHU, Ms. 6, Ser. 5 . 
work problem after problem until they become men of action and not of theory. This, then, is the use of the laboratory in general education, to train the mind in right modes of thought by constantly bringing it in contact with absolute truth. ${ }^{25}$

In several addresses to the public he laid out how the physical laboratory as the means to modern education should look and why it was so important for cultural development:

Those who have studied the present state of education in the schools and colleges tell us that most subjects, including the sciences, are taught as an exercise to the memory. . . The object of education is not only to produce a man who knows, but one who does; who makes his mark in the struggle of life and succeeds well in whatever he undertakes; who can solve problems of nature and of humanity as they arise, and who, when he knows he is right, can boldly convince the world of the fact. ${ }^{26}$

Rowland's remarks are characteristic of a historical process of the late nineteenth century in which modern science understood as the quest for knowledge based on experiment took the lead. But as the case of Rowland shows, in this historical process a clear wedge was driven between the humanities and the natural sciences. This wedge cut off precisely matters of fact from matters of opinion. As he argued, "The facts and theories of our science are so much more certain than those of history, of the testimony of ordinary people on which the facts of ordinary history or of legal evidence rest." 27

In establishing the constant of nature, Rowland's education as an engineer became rather influential and it is not surprising that he aimed at improving the standards of thermometry. In a letter to his boss, the founding president of Johns Hopkins University, Daniel Coit Gilman, he wrote that the standard air thermometer "is the embodiment of my whole work." His publication and the archive materials show that he possessed the most intimate knowledge about the quality of thermometers. Moreover, he regarded this investigation to be of such great importance that he proposed to set up a "sub-department of standards where comparisons were made in absolute measures." Shortly after obtaining his first experimental results he concluded: "Of all the directions in which the department may finally expand, that of thermometry remains very prominent. . . [T] he air thermometer has been taken as the standard and all comparisons will be reduced to the final absolute standard of this perfect gas thermometer." 28

For his research on the mechanical equivalent of heat Rowland did extensive work on the comparison of thermometers then available in Europe and America. Rowland knew that in order to achieve international recognition for scientific knowledge in matters of heat, a standards laboratory was an important measure to take. When he wrote up his

25. Henry A. Rowland, "The Physical Laboratory in Modern Education," The Physical Papers of Henry Augustus Rowland (Baltimore: Johns Hopkins University, 1902), pp.614-8, 617.

26. Henry A. Rowland, ibid., p.617.

27. Henry A. Rowland, "The Highest Aim of the Physicist. Address Delivered as the President of the American Physical Society, at its meeting in New York, October 28, 1899," ibid., pp.668$78,676$.

28. Henry A. Rowland, manuscript, "Physical Laboratory," Johns Hopkins University. "Comparison of Standards. Circular No. I," p.6. JHU Ms. 6, Ser. 5. 
research on the mechanical equivalent of heat for publication, Rowland already felt absolutely certain about his leading position among physicists and attempted to define a new standard of accuracy required for the new millennium:

I have the highest respect for the accuracy of Joule's work, and regard him as a model whom in this respect of care and accuracy which younger physicists would do well to consider. And about one thing we may be certain, that when the scientific millennium is reached, when only physicists of precision remain, we shall ... not have to wait again thirty years to have two physicists agree on what is the true value of such an important quantity as the mechanical equivalent of heat. ${ }^{29}$

Indeed, at Johns Hopkins University Henry Rowland managed to establish a modern standard of precision and accuracy through advanced engineering and rigid physics education that was taken to guarantee reasonable agreement in measurement: a regime of accuracy in which the closeness of fit of numbers required the closeness of fit of humans and machines. ${ }^{30}$

\section{Instruments of precision and the moral economy of accuracy}

Rowland's publication did not mark the end of the process in achieving collective agreement about the value of the mechanical equivalent of heat. To the contrary, his determination led to the unexpected insight that the value of $\mathrm{J}$ was constant only on a limited temperature scale, between $15^{\circ}$ and $25^{\circ} \mathrm{C}$. Although his findings and the accuracy of "two parts in one thousand" were undoubtedly a tremendous achievement in the drive to increase the precision and sensitivity of measurements, they simultaneously showed the limited scope of this knowledge claim and the ambivalent character of precision measurement. When precision techniques were used to achieve more certainty, they sometimes produced unexpected discoveries, such as the changing specific heat of water at various temperatures. Furthermore, the value of a physical constant continued to depend on the skills of the investigators and the instruments they used. Rowland's achievements left behind some serious questions. Was the mechanical equivalent a constant of nature, or a simple artifact of the experimental set-up? Did this constant exist over the full temperature scale? What was the meaning of $\mathrm{J}$ ? The following forty years saw an attempt to resolve these issues collectively; an international community of scientists was engaged in improving the high standards of precision measurement. For most of these investigators, the unity of the physical sciences hinged on high-caliber

29. Rowland's unfinished concluding sentences and parts of sentences are to be found in his draft on "Appendix to Paper on the Mechanical Equivalent of Heat, Containing the Comparison with Dr. Joule's Thermometer," JHU, Ms.6, Box 39, Series 5, the author's emphasis. For the published version see Henry A. Rowland, "Appendix to Paper on the Mechanical Equivalent of Heat, Containing the Comparison with Dr. Joule's Thermometer," Proceedings of the American Academy of Arts and Sciences 16 (1880): 38-45.

30. For a detailed exploration of Henry Rowland's contribution to establish this fact see Sibum, "Exploring the Margins" and "An Old Hand" (note 21). 
precision work, but the quality of precision measurement always depended on the skills of particular scientists and the particularities of places. Every improvement in precision required an increased accuracy on the part of the investigators' performance - skills that had to be acquired collectively.

In his presidential address to the BAAS in 1906, the physicist E. H. Griffiths summarized the development of the preceding two decades:

It is true that the results of Rowland's classical investigation were published in 1880 and 1881 , but this discrepancy between his conclusions and those of Regnault regarding the change in the specific heat of water at temperatures between $0^{\circ} \mathrm{C}$. and $30^{\circ} \mathrm{C}$. introduced an element of uncertainty. As a consequence of this discrepancy much experimental work on the subject has been performed in the last quarter of a century, and I think it may be said without hesitation that the value of this important constant is now ascertained with an accuracy of about one part in 2,000 . The amount of labour which has been employed in the determination of this thermal constant is extraordinary, and, as I have pointed out elsewhere, it well illustrates the cosmopolitan character of scientific investigation ${ }^{31}$

One of the fundamental issues to be resolved in this cosmopolitan endeavor of the last two decades of the nineteenth century was reliable thermometric measurement. In private correspondence with Rowland, the German doyen of precision measurement Friedrich Kohlrausch spelled out quite clearly the problem of maintaining precision:

[W] ought to guarantee a $1 / 1000$ of an error at the most, if an international laboratory wants to bestow unity upon science and technology. For this purpose the laboratory has to work much more precisely than physicists have currently done. . To bring a number of experienced physicists for this purpose permanently together seems impossible. Every one of us certainly knows that he would work best at home. ${ }^{32}$

Instead, initiatives to compare or improve thermometers came into existence in every country that began in the late nineteenth century to set up scientific standards organizations, such as the BAAS standards committees, the Kew Observatory that became part of Britain's National Physical Laboratory in 1900, the Physikalisch-Technische

31. E. H. Griffiths, "Presidential Address' to the British Association for the Advancement of Science," BAAS Science, New Series 24 (1906): 353-65, 359. E. H. Griffiths was one of the leading physicists (Fellow of the Royal Society, 1895) engaged in the determination of the mechanical equivalent of heat pursuing the indirect method, i.e. employing the electrical method. After having designed a platinum resistance thermometer he started work first in the laboratory of Sydney Sussex College in Cambridge but later on even in a special private laboratory built in his garden. R. T. Glazebrook, “Dr. E.H. Griffiths, F.R.S.”, Nature 129 (3256) (1932): 461-2.

32. "Ich meine das die Verbürgung auf höchstens $1 / 1000$ Fehler vorausgesetzt werden muß, wenn ein internationales Laboratorium die Einheit von Wissenschaft und Technik octroyren will. $\mathrm{Zu}$ diesem Zwecke aber müßte dieses Laboratorium wesentlich genauer arbeiten, als die Physiker bis jetzt gethan haben. . . Eine Anzahl erfahrener Physiker aber zu diesem Zwecke dauernd zu vereinigen, wird unmöglich sein. Es weiß ja auch jeder von uns, daß er zu Hause am besten arbeitet," Kohlrausch to Rowland, April 28, 1882, JHU, MS 6. 
Reichsanstalt (PTR) in Germany, and the National Bureau of Standards founded in the United States in $1901 .{ }^{33}$ Moreover, various physics laboratories, such as Henry Rowland's at Johns Hopkins University, made intensive standards measurements in order to settle disputes over temperature measurements. ${ }^{34}$ Already in the $1880 \mathrm{~s}$ members of the PTR under the guidance of Wilhelm Förster had performed extensive research on the accuracy of mercury and gas thermometer readings. H. F. Wiebe collaborated with the Jena glass manufactory C. Schott and brought the most important improvements to thermometry: they found that thermometer glass should either contain sodium or potassium. Glass containing either element - not as a mixture - dramatically reduced its thermic depression, which previously had caused severe errors in thermometer readings. ${ }^{35}$

Whereas research on thermometry funded by the German state at the PTR in collaboration with Jena's glass firm was showing great success and promoted the direct method of determining the mechanical equivalent of heat, the standards of temperature measurement in Britain lagged behind. Kew Observatory's program of standardizing thermometers failed to reach the standards of physical investigation:

I do not wish in any way to disparage the standardisations performed at Kew, but it is evident that they do not meet, and I conclude are not intended to meet, the demands of exact inquirers.

33. On the work of the BAAS standards committee see, for example, Schaffer, "Accurate Measurement" (note 10); Lee T. Macdonald, Kew Observatory and the Evolution of Victorian Science, 1840-1910 (Pittsburgh: University of Pittsburgh Press, 2018); Russell Moseley, "The Origins and Early Years of the National Physical Laboratory: A Chapter in the Prehistory of British Science Policy," Minerva, 16(2) (1978): 222-50; David Cahan, An Institute for an Empire: The Physikalisch-Technische Reichsanstalt 1871-1918 (Cambridge: Cambridge University Press, 1989); Rexmond C. Cochrane, Measures for Progress: A History of the National Bureau of Standards (National Bureau of Standards, U.S. Department of Commerce, 1966).

34. The latter even published an appendix to his paper on the mechanical equivalent of heat which contains comparisons with Joule's thermometer. Rowland's student William S. Day at Columbia University in New York made an extensive comparison of his thermometers with the Paris standard with the aim to reduce the value of the mechanical equivalent of heat to the more widely accepted hydrogen temperature scale. William S. Day, "A Comparison of Rowland's Thermometers with the Paris Standard, and a Reduction of his Value of the Mechanical Equivalent of Heat to the Hydrogen Scale," The Physical Review (1898): 193222; Henry A. Rowland, “Appendix” (note 29). Arthur Schuster did extensive work on determining the scale-value of Joule's original thermometer used in his famous experiments and in comparing Joule's thermometer with the standards of the Bureau International des Poids et Mesures at Sevrès. A. Schuster, "Dr Joule's Thermometer," Nature 47 (1893): 364; "On a Comparison of the Thermometers Used by the Late Dr. Joule with the Standards of the Bureau International des Poids et Mesures," Memoirs and Proceedings of the Manchester Literary and Philosophical Society 9 (1894-5): 87-91; "On the Scale-Value of the Late Dr. Joule's Thermometer," Philosophical Magazine 39 (1895): 477-501; see also Sidney Young, "Dr. Joule's Thermometers," Nature 47 (1893): 389-90.

35. Schott used glass which had a depression of $1^{\circ}$ in $100^{\circ} \mathrm{C}$, then produced borosilicate glass which had a depression of $0.05^{\circ} \mathrm{C}$, which agrees with the standards of precision for hydrogen thermometers. See "The Construction of Standard Thermometers," Nature 52(87) (1895); on the metrological contributions from the PTR see W. Foerster (ed.) Thermometrische Untersuchungen (Berlin, 1881). 
Very wisely they do, in no case, give the correction term beyond $0.01^{\circ} \mathrm{C} ., \ldots$ I am afraid that the issuing of those Kew certificates, which give the second decimal figure of the correction, so far from being a prevention is a cause of inaccuracy, as, unless used with a full knowledge of the variations consequent on changes in the conditions, they impart a false confidence to their possessors. ${ }^{36}$

Whether individually or through their standards committees, British researchers had to develop their own techniques to match the standard of precision achieved on the continent. At Cambridge University, the 'home of standards', H. L. Callendar and E. H. Griffiths were instrumental in overcoming this problem by developing and introducing a new standard of accuracy in heat measurements using an electrical thermometrical method. Based on W. Siemens' experience with producing an electrical pyrometer for commercial purposes, in 1887 Trinity College Cambridge fellow H. L. Callendar began developing the platinum resistance thermometer as a new scientific instrument.

Together with Ezer Griffiths ${ }^{37}$ and G. M. Clark, Callendar pursued the project of making and probing the scientific use of the platinum thermometer that finally led to the marketing of the device by Horace Darwin's Cambridge Scientific Instrument Company. This device became the key tool in raising the standards of accurate performance: it was expected to resolve the remaining discrepancies in the values of $\mathrm{J}$ and the restricted validity of this number resulting from the changing thermal properties of water. An electrical determination of $\mathrm{J}$ based on the high standards of precision electrotechnology was indeed a promising path, as determinations of electrical units in absolute measure were accurate to 1 part in 10,000 compared to direct measures of temperature (1 in 2,000).

The development of both techniques, the direct measurement method with glass thermometers in Germany and the indirect method using the Cambridge platinum thermometers, led to a reciprocal improvement and control of the standards of precision instrumentation and accurate performance. These investigations finally culminated in an outstanding international effort to define the absolute thermal unit. ${ }^{38}$ Practically all eminent physicists at the time contacted by Griffiths agreed on the necessity of such an absolute unit of heat. The biggest obstacle was the instability of the specific heat of water over the full temperature range, which meant that several units continued to be in use. Griffiths' initiative thus found interest with most physical scientists and stimulated new

36. E. H. Griffiths, “The Measurement of Temperature," Science Progress 2 (1894-5): 64-80, 68-9.

37. Ezer Griffiths has no family relationship to E. H. Griffiths but came under the influence of the latter. With the latter Ezer started his work on the theory of heat that became his life's study. From 1915 onwards he became a leading physicist in the Heat Division of the British National Physical Laboratory. He collaborated with E. H. Griffiths on the heat capacity of metals and published extensively on methods of temperature measurement. Charles G. Darwin, Biographical Memoirs of Fellows of the Royal Society 8 (November 1962): 41-8.

38. H. L. Callendar, "On the Construction of Platinum Thermometers," Philosophical Magazine, Series 5, 32 (1891): 104-13; on the measures taken to establish the absolute thermal unit as part of the absolute system of units see "Experiments for Improving the Construction of Practical Standards for Electrical Measurements," BAAS Report 1 (1896): 150-61 and BAAS Report 1 (1897): 206-9, see also E. H. Griffiths, "The Thermal Unit," Philosophical Magazine, Series 5, 15 (1895): 431-54. 
investigations on the value of the mechanical equivalent of heat at various temperature levels and using different means in order to finally agree on the exact work value of the thermal unit. ${ }^{39}$ Without going into detail about these various investigations it is essential to note that despite these efforts, agreement about a reliable value remained very difficult to achieve. Hence Griffiths already concluded in 1895 that "further individual effort will avail but little, what is necessary is the decision of some body having authority, whose conclusions will command the respect and assent of the scientific world." 40

He was not the only one who stressed that now and in the future any top research would depend on a well-functioning network of scientists in which instruments of precision and skills are exchanged. Even theoretically inclined physicists like Ludwig Boltzmann noticed this important moment of change. "If therefore a genius often achieves the greatest results with smallest resources, we here see the opposite, that it requires the enormous perfection of present day instruments of observation and experimental technique before the human intellect can achieve certain kinds of result." ${ }^{41}$ This level of perfection could only be achieved collectively, through the work of many performed at different places in the industrial world. With regard to the mechanical equivalent of heat it was the network established among Berlin, Baltimore, Pisa, Zurich, Montreal, Manchester, and Cambridge that Griffiths listed as being responsible for providing not only certainty of the value of $\mathrm{J}$ but also discovering a hitherto unsuspected cause of inaccuracy in the absolute system of electrical units.

It may possibly appear that the result just quoted is a somewhat poor return for the expenditure of so much thought and labour. I would call attention, therefore, to the fact that the value of this equivalent is dependent on the measurements of many other natural constants; hence any agreement between the results obtained by the observations of Rowland and some of the other observers I have mentioned would only be possible in the absence of errors of appreciable magnitude in the determination of mass, of change of temperature, and of electrical resistance and current. Certain discrepancies have led to the discovery of a hitherto unsuspected cause of inaccuracy, especially in the determination of temperature, and thus the inquiry has rendered valuable service in many branches of physical inquiry. ${ }^{42}$

At the beginning of the twentieth century this international network of scientists had managed to establish mutual trust in their performances of measurement and standards of accuracy. And yet reasonable agreement about the correct value of $\mathrm{J}$ was still impeded through various further redeterminations of the mechanical value of heat. ${ }^{43}$ In both

39. See Griffiths, "The Thermal Unit" (note 38).

40. Griffiths, ibid., p.454.

41. L. Boltzmann, "On the Development of the Methods of theoretical Physics in Recent Times," 1899, in L. Boltzmann, Theoretical Physics and Philosophical Problems (B. McGuinness, ed.) (Dordrecht and Boston: D. Reidel, 1974), pp.77-100.

42. E. H. Griffiths, "The British Association for the Advancement of Science. Address before the section of Mathematics and Physics," Science, New Series, 24, 612 (1906): 353-65, 359.

43. Some of the most important determinations of the mechanical equivalent of heat are M. C. Miculescu, "Sur la determination de l'equivalent mecanique de la calorie," Annales de Chimie et de Physique 27 (1892): 202-38; E. H. Griffiths, "The Value of the Mechanical Equivalent of 
research strands that were pursued at the turn of the century, that is, in the direct method (mechanical stirring of water that effected an increase in temperature) as well as the indirect method (heating of water by means of an electric current was described as the indirect method) thermometry remained one of the key issues still to be resolved. Within that international community these competing efforts in achieving agreement about the correct value of $\mathrm{J}$ demonstrated the mutual dependency and fragility of this absolute system of units. Achieving agreement on the value of this physical constant not only required the exchange of precision technologies but equally so mutual trust in the performance of men and machines. With the tremendous efforts in establishing the absolute system of units in Europe and North America the determination of electric units came to be considered more highly accurate than the thermal units. ${ }^{44}$ Hence within that community leading physicists became more and more convinced that the indirect method of determining $\mathrm{J}$ was much more reliable than the direct method, simply for the reason that the use of an electrical platinum thermometer and a standardized wire would 'naturally' guarantee that high standard of accuracy that was achieved in the determination of the electrical units.

Finally, on December 11, 1925, the Physical Society of London received a letter suggesting a "critical discussion of the determinations of the mechanical equivalent of heat." 45 Its author, the Australian physicist T. H. Laby from the University of

Heat, Deduced from Some Experiments Performed with the View of Establishing the Relation Between the Electrical and Mechanical Units, Together with an Investigation into the Capacity for Heat of Water at Different Temperatures," Philosophical Transactions 184 (1894): 361-504; Osborne Reynolds and W. H. Moorby, "On the Mechanical Equivalent of Heat," Philosophical Transactions 190 (1898): 301-422. For a detailed listing of these activities see Karl Scheel (ed.), Verhandlungen der deutschen Physikalischen Gesellschaft im Jahre 1908 (Braunschweig, 1908), pp.584-90; J. S. Ames, "L'equivalent méchanique de la chaleur" and E.H. Griffiths, "Chaleur specifique de l'eau," Appendice, in Ch.-Èd. Guillaume and L. Poincaré (eds), Rapports Presentes Au Congrès International de Physique Réuni a Paris en 1900 Sous les Auspices de la Societe Francaise de Physique, Vol. 1 (Paris, 1900), pp.178-213 and 214-26; E. Warburg, Referat über die Wärmeeinheit erstattet in der gemeinschaftlichen Sitzung der Sectionen für Physik und angewandte Mathematik und Physik am 22. September 1899 auf der Naturforscher-versammlung in München (Leipzig, 1900), pp.3-19; Johann Pernet, "Über die Änderung der specifischen Wärme des Wassers mit der Temperatur und die Bestimmung des absoluten Wertes des mechanischen Wärmeäquivalentes der Wärmeeinheit," Vierteljahresschrift der Naturforschenden Gesellschaft in Zürich (1896): 121-48; E. Lüdin, Die Abhängigkeit der spezifischen Wärme des Wassers von der Temperatur (Ph.D. dissertation, Zürich, 1895).

44. On the absolute system of units see Schaffer, "Accurate Measurement" (note 10); Simon Schaffer, "Modernité et Mètrologie," in Kapil Raj and H. Otto Sibum (eds), Histoires des Sciences et des Savoirs. Vol. 2. Modernité et Globalisation (Paris: Le Seuil, 2015), pp.11541; Hunt, "The Ohm" (note 12); Joseph O'Connell, "Metrology: The Creation of Universality by the Circulation of Particulars," Social Studies of Science 23 (1993): 129-73; for the difficulties encountered in international electrical standardization at the end of the nineteenth century see, for example, Michael Kershaw, "The International Electrical Units: A Failure in Standardisation?" Studies in History and Philosophy of Science 38 (2007): 108-31.

45. Laby, "Critical Discussion," (note 2). His final determinations were published as T. H. Laby and E. O. Hercus, "The Mechanical Equivalent of Heat," Philosophical Transactions of the Royal Society of London. Series A, Containing Papers of a Mathematical or Physical Character 227 (1928): 63-91. 
Melbourne, was a newcomer to this distinguished group of scientists involved in metrology, but with some strong ties built up through his undergraduate education (BA) and fellowship work at the Cavendish Laboratory at Cambridge University from 1905 until 1909. J. H. Poynting, J. J. Thomson, and E. Rutherford had been enthusiastic about this young settler scientist whose talent in experimentation excelled the usual Cambridge students. And it was without surprise that Laby soon would receive a chair in physics in Australia. From 1909 until 1915 he worked at Victoria University College, Wellington before he moved on to take the chair of natural philosophy at the University of Melbourne. ${ }^{46}$ Before he left for his second research stay in Cambridge in 1920 he had just finished a collaborative research project "on a new method of determining the mechanical equivalent of heat" to be published that year in the journal of the Royal Society of Victoria. ${ }^{47}$

With his letter to the Physical Society, Laby aimed at bringing his research to the attention of a powerful elite by critically discussing the principal recorded determinations of the mechanical equivalent of heat "and to correct them for possible errors not fully taken into account at the time they were made." The results are weighted according to the (in)sufficiency of accuracy judged by the author, "and the weighted mean is given as 4,184 joules per calorie at 20 degrees" (Fig. 1). ${ }^{48}$ Claiming that the value of J achieved by his predecessors by means of direct determinations was less than ten times the accuracy of what he had achieved was already a bold statement, likewise the display of the limits of accuracy of his fellows' indirect electrical determinations. By doing so, Laby was running the risk to scrutinize the self-imposed standards of conduct of research of his predecessors. ${ }^{49}$

Whereas several members of the Physical Society viewed Laby's proposal with certain misgivings, some were impressed. The British physicist Ezer Griffiths - undoubtedly one of the experts in precision measurement - acclaimed that "if accuracy of such

46. Laby was awarded an Exhibition of 1851 Overseas Research Studentship followed by a Joule Studentship of the Royal Society. On Laby as settler scientist see Katrina Dean, Settler Physics in Australia and Cambridge, 1850-1950 (Ph.D. Dissertation, Cambridge University, 2004); Tamson Pietsch, Empire of Scholars: Universities, Networks and the British Academic World 1850-1939 (Manchester: Manchester University Press, 2013), pp.109-24; H. S. W. Massey, Obituaries Prof. T.H. Laby, F.R.S. Nature 4005 (August 3, 1946): 157. Cecily Close, "Laby, Thomas Howell (1880-1946)," Australian Dictionary of Biography, vol. 9 (Melbourne University Press), 1983;

47. T. H. Laby and J. K. Roberts, "A New Method of Determining the Mechanical Equivalent of Heat," Proceedings of the Royal Society of Victoria, 32 (N.S.), Part II (1920): 148-55.

48. Laby, "Critical Discussion," p.169 (note 2). One should note, however, that the given value "4,184 Joules per calorie at 20 degrees" in the abstract remains unjustified in the "Critical Discussion" paper in which the weighted mean value of the various listed determinations of $\mathrm{J}$ is given as 4,182 . It seems that Laby has deliberately or by mistake announced already his freshly achieved result (of 4,1841 for a calorie at $16.7^{\circ} \mathrm{C}$ which was equivalent to 4,1809 at $20^{\circ} \mathrm{C}$ ) going to be published in the final paper "On the Mechanical Equivalent of Heat" in the Philosophical Transactions of 1928. T. H. Laby and E. O. Hercus, "The Mechanical Equivalent of Heat" (note 45).

49. Laby and Roberts, "A New Method" (note 47). 
an order is possible there can be no doubt of its desirability." ${ }^{50}$ But despite this promise of improved accuracy, several distinguished physicists expressed strong reservations at the meeting when the paper was read, if they were not embarrassed to see someone questioning the earlier work of gentlemen. Although G. M. Clark - a co-worker with E. H. Griffiths on the determination of J in the years 1887 until 1892 - welcomed the prospect of improving accuracy, he expressed his misgivings as follows:

I doubt whether much is gained by discussing the results of other observers by making known corrections that arise through the light of later knowledge. Every physical determination is a shot at a target, and by the removal of certain errors it is by no means certain that the remainder give a better probable value for the centre of the target. ${ }^{51}$

The metaphor of shooting at a target has become the new way of evaluating the practice of precision measurement in science among twentieth-century physicists, with strong implications for the meanings of the terms accuracy and precision. Accuracy, previously understood as a way of conduct, "doing with care, nicety of attention" (from lat. accurare), now indicated the closeness of measurements to the true value. Precision now meant how close the measured values are to each other. ${ }^{52}$ This turns Griffiths' remark into a particularly strong criticism of Laby's attempt; removing certain errors from old measurements does not imply that the true value (the center of the target) is more likely to be identified. It could just mean that you have increased precision of the old measurements. Furthermore, in the same way as Clark was of the opinion that only the person "who can revise any old determination is the person who made it," Griffiths could accept revisions of old results only if they were achieved together with the investigators whose work had been corrected. Hence he proposed: "In the present instance many of the investigators whose work had been corrected by Prof. Laby are still living, so they can make their views known before Prof. Laby writes his final account." ${ }^{93}$

The controversy over his weighting of previous results shows that maintaining an acceptable value for $\mathrm{J}$ with an accuracy of 1 in 10,000 hinged on complex negotiations about an exchange of the physical techniques deployed, the instruments of precision used, and the means of representing data produced in the experiment. For the future, Griffiths suggested that:

In the publication of work of high precision some authorities advocate the insertion of data in great detail, so as to facilitate subsequent corrections. The plan I would like to suggest is that the investigator should preserve his apparatus, so that the experiments can be repeated with

50. Ezer Griffiths in Laby, "Critical Discussion,” p.173 (note 2). See also Ezer Griffiths, Methods of Measuring Temperature (London: Chas. Griffin \& Co, 1918); Ernest Howard Griffiths and Ezer Griffiths, "The Capacity for Heat of Metals at Low Temperatures," Philosophical Transactions of the Royal Society of London. Series A, Containing Papers of a Mathematical or Physical Character 214 (1914): 319-57.

51. G. M. Clark in Laby, "Critical Discussion," p.173 (note 2).

52. This understanding of precision and accuracy still implies, for example, that you can be precise without being accurate, i.e. all your shots are very close to each other (you are precise) but all these shots missed the center of the target (the true value).

53. Griffiths in Laby, "Critical Discussion," p.173 (note 2). 
such modifications as experience dictates. It will, I think, be generally admitted that the development of the method and the technique absorbs most of the time in an investigation, so a repetition would not be a formidable undertaking. ${ }^{54}$

If the repetition of an experiment consumed valuable time and labor and was therefore not advisable, the question remained: what other techniques of assessing the experimenter's testimony for a factual knowledge claim could be applied? Griffith proposed making public all the data produced in experimental runs and preserving the apparatus for later evaluations, ideas that were met with approval by the participants in the meeting.

And yet Laby's proposal was still met with certain misgivings because his colleagues regarded the questioning of the accuracy of his predecessors as disrespectful to the work of other gentlemen who were involved earlier on. In the culture of precision, the moral economy of accuracy was deeply intertwined with a lived gentlemanly ethos, which emphasized being honest, having strong moral principles, and high standards of doing one's own work. Moreover, G. M. Clark reminded his colleagues, this resentment toward replicating experiments would unnecessarily cover a much deeper epistemological aspect that lies in precision experimentation:

The tables put forward by the author are, however, not only of use for the point that the author wishes to make - namely, the necessity for revision - but they are also of use as showing that the halo of nebulosity surrounding any physical determination is probably greater than the original experimenter cared to acknowledge to himself..$^{55}$

That any physical determination is surrounded by 'a halo of nebulosity' that not even the experimenters themselves would be aware of is today a well-known topic in science studies on replication of experiment. But for any person of integrity within this community gathering at the Physical Society this was a rather uncomfortable thought. ${ }^{56}$ Thanks to Clark's rather open-minded and self-critical comments on his own older work in determining $\mathrm{J}$, he could counterbalance this objectionable thought by emphasizing the power of the author's truly cosmopolitan enterprise of engaging with the experimental results of others that would dissolve the nebulosity and resolve the remaining discrepancies in values of this physical constant. Hence Clark said:

I admire very much the author's apparatus and equipment and contrast it with our own of nearly forty years ago... [I]t was impossible at that time to get small electric motors. . Over two years of our time were spent in research into thermometry, which was a side show to the main

54. Ibid.

55. Clark in Laby, "Critical Discussion," p.173 (note 2).

56. Because the performance of an experimental trial often depends on some tacit knowledge a successful replication of an experiment requires the transfer of this embodied knowledge. On tacit knowledge see Michael Polanyi, Personal Knowledge: Towards a Post-critical Philosophy (Chicago and London: University of Chicago Press, 1958); Collins, Changing Order as well as Tacit and Explicit Knowledge (note 8); for a historical study see H. Otto Sibum, "Les gestes de la mesure. Joule, les pratiques de la brasserie et la science," Annales Histoires, Sciences Sociales, 53(4-5) (1998): 745-74. 
determination, but involved such work as the development of the platinum resistance thermometer, and the fixing of its standardisation point, the boiling point of sulphur. I envied the author his being able to start up with much more modern equipment. . . I wish him every success in his work and feel that he can do it whole-heartedly as one who has already been thoroughly over the ground in every detail. ${ }^{57}$

\section{Conclusion}

Clark's reference to his own past in having to work with insufficient equipment and admiring the modern standards of precision instrumentation Laby was equipped with may have provided a common rationale for understanding Laby's ambition to redetermine J. Furthermore, it may have made his critical discussion of earlier works performed by esteemed colleagues and friends if not worthwhile then at least tolerable. In fact many of the scientists present at the Physical Society meeting knew firsthand of the nineteenth-century struggles in establishing and achieving a true value of $\mathrm{J}$ and of the high demands of accuracy this kind of research afforded. No doubt, anyone who dared question previous work in this cosmopolitan achievement would have met strong opposition. The Australian physicist Laby, then only known by a few but powerful members of the international physics community, certainly was aware of this and hence launched this critical discussion at the Physical Society of London after he had already introduced his "New Method of Determining the Mechanical Equivalent of Heat" in an earlier paper published in the Proceedings of the Royal Society of Victoria ${ }^{58}$ He regarded these as preparatory steps in his effort to publish the final paper, "On the Mechanical Equivalent of Heat," in the prestigious Philosophical Transactions of the Royal Society. The critical discussion wasn't to him in any way unsettling. On the contrary, he was encouraged in publishing the new results that he and his collaborator O. E. Hercus had measured as soon as possible because they demonstrated 'modern standards of accuracy'. Finally, in February 1927 his mentor and then president of the Royal Society communicated his co-authored paper, "The Mechanical Equivalent of Heat," to that society. It was unanimously accepted and, as the absence of any further commentaries or critical discussions indicates, it finally closed the debate over correct values of J. ${ }^{59}$

In that paper Laby and Hercus succeeded in demonstrating a standard of accuracy in conducting research in a way that allowed the reader to have trust and confidence in the methods used and the findings that result from them. Even professional standards could continue to advance. The key was their use of platinum resistance thermometers. These devices provided the link to the well-established and shared practices of electrical measurement as employed in industrial complexes used in the international telegraphic network. Hence members of this scientific community regarded it as the most sensitive and reliable precision technology. This advanced measuring device, its application to the direct determination of the friction of water, and Laby's performance of accuracy

57. Clark in Laby, "Critical Discussion," p.174 (note 2). The actors do not, however, reflect on the epistemological issues involved in replication, i.e. the experimenter's regress problem as discussed in Collins, Changing Order (note 6).

58. T. H. Laby and J. K. Roberts, "A New Method of Determining the Mechanical Equivalent of Heat" (note 47).

59. T. H. Laby and E. O. Hercus, "The Mechanical Equivalent of Heat" (note 45). 
recognized as personal integrity in this social network became key elements in a specific historical constellation that made the scientific community decide when reasonable agreement about the correct value had been achieved - when enough is enough (Fig. 1).

To conclude, in science achieving 'reasonable agreement' about experimental data is not a universally shared practice - it changes over time and place. Particularly the historical actors' specific understanding of what constitutes 'sufficient accuracy' in conducting research matters a great deal in achieving reasonable agreement. In the early twentieth century 'accuracy' still addressed the integrity of the researchers, implying that they were honest, and had strong moral principles and high standards of performing work. Furthermore, the understanding that replication of experimental results guarantees integrity of scientific research was not established in the early twentieth century. The term 'replication' was not yet used; instead 'repetition of experiment' was practiced. But as we have seen, it was regarded with certain misgivings. Publicly discussing diverging experimental results always implies a public evaluation of the conduct of research. Hence engaging with experiments of those who were not alive any longer was considered a waste of time and even impolite. Nevertheless, Laby's proposal passed and his publication silenced previous controversial accounts about the 'true value' of the mechanical equivalent of heat. But Laby succeeded in demonstrating sufficient accuracy in his research by employing, first, the most trustworthy precision technology developed in collaboration with the electrical industry, the platinum resistance thermometer; second, the material improvement of previous experimental set-ups; and third, the backing of leading members of the British scientific community who credited him as an outstanding researcher. ${ }^{60}$ Together these elements won Laby recognition within the scientific community and strengthened the conviction that agreement had been achieved - at least for some time.

\section{Declaration of conflicting interests}

The author declared no potential conflicts of interest with respect to the research, authorship, and/ or publication of this article.

\section{Funding}

The author received no financial support for the research, authorship, and/or publication of this article.

\section{ORCID iD}

H. Otto Sibum iD https://orcid.org/0000-0001-6438-9789

60. During the early years of his career as a physicist and chemist Laby had the opportunity to work with some important scientists of the day, such as J. J. Thomson in Cambridge and Ernest Rutherford. Thomson regarded him as the most skilled experimenter unexcelled in his time. With the latter he and his family established a close relationship and Rutherford acted for some time as Laby's mentor and advisor. See Ed Muirhead, A Man Ahead of His Time: T. H. Laby's Contributions to Australian Science (Melbourne: The University of Melbourne, 1996), 3-9. 


\section{Author biography}

H. Otto Sibum is Hans Rausing Professor of History of Science and Director of the Office for History of Science at Uppsala University, Sweden. His research focuses on the social and cultural history of the physical sciences. 